\title{
Michael J. Gardner and Judith Siegel: Minimally invasive orthopaedic trauma. Series editor: Paul Tornetta III
}

\section{Lippincott, Williams \&Wilkins, a Wolter Kluwers Business, Hardback, December 2013, 178 pp, List Price: $£ 152.00$, ISBN: 978-1-4511-1474-4}

\author{
Alain G. Graftiaux
}

Received: 15 December 2014/Accepted: 28 December 2014/Published online: 6 March 2015

(C) Springer-Verlag France 2015

The first chapter treats biological bases of minimally invasive osteosynthesis and then follows the chapters on the specific fractures of the upper and lower limbs.

Each time, the indications, the techniques according to the various types of fracture, the complications and the outcomes are analysed.

One will be able to regret the absence of discussion of the various indications, with advantages and disadvantages of the open techniques. Discussion is often skimmed to justify the minimally invasive technique.

In addition, this book is very practical with many drawings and photographs, as well as councils of use to facilitate the training of the techniques.

In addition, an access online is provided.

Conflict of interest None.

A. G. Graftiaux ( $\square)$

Strasbourg, France

e-mail: graftiaux.alain@neuf.fr 